\title{
Beginning of sediment transport of incoherent grains in shallow shear flows
}

\section{Marco Pilotti \& Giovanni Menduni}

To cite this article: Marco Pilotti \& Giovanni Menduni (2001) Beginning of sediment transport of incoherent grains in shallow shear flows, Journal of Hydraulic Research, 39:2, 115-124, DOI: 10.1080/00221680109499812

To link to this article: http://dx.doi.org/10.1080/00221680109499812

$$
\text { 曲 Published online: } 01 \text { Feb } 2010 .
$$

Submit your article to this journal

Цlll Article views: 130

Q View related articles $\sqsubset$

7 Citing articles: 19 View citing articles 


\title{
Beginning of sediment transport of incoherent grains in shallow shear flows Début du transport de sédiments non cohésifs dans les écoulements visqueux peu profonds
}

\author{
MARCO PILOTTI, Dipartimento di Ingegneria Civile, Università degli Studi di Brescia, 38, Via Branze, 25123 Brescia, Italy \\ GIOVANNI MENDUNI, DIIAR, Politecnico di Milano, 32, Piazza Leonardo da Vinci, 20133 Milano, Italy
}

\begin{abstract}
In this paper the main results of an experimental investigation on the beginning of sediment transport of incoherent granular materials in shallow viscous flows are presented. The experiments, performed in a laboratory flume in both laminar and smooth turbulent flow conditions, complement the data already available in literature, and confirm that the hyperbolic trend shown by the Shields curve when the grain Reynolds number $X$ decreases to zero is not supported by experimental evidence. In addition, they confirm the Yalin and Karahan (1979) hypothesis on the existence of a distinct curve for the inception of sediment transport in viscous dominated flows. On the basis of the observed phenomenology, we propose to interpret the process as a function of the probability distribution of the repose angle of the grains of the erodible bed. Accordingly, a simple mechanical relation is derived that explains the pattern exhibited by the experimental data.
\end{abstract}

\section{RÉSUMÉ}

Dans cet article sont présentés les principaux résultats d'une étude expérimentale sur le début du transport de sédiments de matériaux non cohésifs dans les écoulements visqueux en faible profondeur. Les expériences, effectuées dans un canal en laboratoire, sur des écoulements laminaires et faiblement turbulents, complètent les données de la littérature disponibles actuellement, et confirment le fait que le comportement hyperbolique montré par la courbe de Shields n'est pas vérifié expérimentalement quand le nombre de Reynolds du grain, X, tend vers zéro. De plus, elles confirment l'hypothèse de Yalin et Karahan (1979) sur l'existence d'une courbe distincte pour le début du transport de sédiments dans les écoulement à viscosité prépondérante. Sur la base des phénomènes observés, nous proposons d'interpréter le processus comme une fonction de la loi de probabilité de l'angle de repos des grains du lit érodable. On en déduit alors une relation mécanique simple qui explique la forme des données expérimentales.

\section{Introduction}

Considering a two dimensional steady free surface flow on an initially plane bottom, a typical bed load relation is given as

$$
\Pi_{q}=\stackrel{q}{\rho v_{*}^{3}}=\varphi(X, Y, Z, W)
$$

where the adimensional solid discharge $\Pi_{q}$ is a function of the adimensional groups

$$
\begin{aligned}
& X=\begin{array}{c}
\rho v_{*} D \\
\mu
\end{array} \\
& Y=\begin{array}{l}
\rho v_{*}^{2} \\
\gamma_{s} D
\end{array}=\tau_{\gamma_{s} D} \\
& Z=\begin{array}{l}
h \\
D
\end{array} \\
& W=\begin{array}{l}
\rho_{s} \\
\rho
\end{array}
\end{aligned}
$$

Given the dependence of the bed load discharge on the dimensionless bottom shear stress $Y$, if one agrees that a critical threshold of the shear exists, $\tau_{c r}$, below which an erodible bed can be regarded as fixed, then equation (1) can be rewritten as follows

$$
\Pi_{q}=\varphi\left(X, Y-Y_{c r}, Z, W\right)
$$

This structure is common in several bed load discharge formulas. Apart from the formula by DuBoys (1879) and the one by Shields (1936), this is the case of widely used equations such as, inter alia, the equation proposed by Meyer-Peter and Müller (1948), by Yalin (1963) and by Chang, Simons and Richardson (1967). From equation (6) it turns out that a basic problem in the field of sediment transport is identifying the function

$$
Y_{c r}=Y_{c r}(X, Z, W)
$$

This represents the conventional threshold between single-phase flows and two-phase flows. The problem has been addressed for the first time in terms of similitude by Shields (1936). According to Shields, equation (7) can be simplified as a function of the grain Reynolds number $X$ only,

$$
Y_{c r}=f(X)
$$

as confirmed by the measurements that the author made in the range $X>2$ (that do not exhibit any clear dependence on the adimensional group $Z$ ), and as suggested by the meaning of the variable $Z$ and $W$ (e.g., Yalin, 1977).

The graphic representation of (8), known as Shields diagram, is 
possibly one of the most frequently cited relationships in the field of sediment transport (e.g., Lavelle and Mofjeld, 1987b) and is certainly the most widely accepted criterion for the determination of the beginning of sediment transport. However, while the dependence of the solid bed load discharge on the average bottom shear stress $\tau_{o}$ is clear, the meaning to be given to the word critical stress, $\tau_{c r}$, is far from evident. Considering turbulent flow conditions, it has often been observed (e.g., Lavelle and Mofjeld, 1987a) that it is not possible to detect a threshold below which the bed is strictly fixed. This fact is also supported by Einstein's bed load function, whose statistical representation of the inception of sediment transport leads to a formulation without any lower cutoff. Accordingly, it seems reasonable to distinguish between the terms beginning of sediment motion and beginning of sediment transport. The former results as deprived of meaning, in consideration of the random nature of the grain entrainment process. The latter instead retains a conventional value that requires the explanation of the criterion used in its definition (e.g., Pilotti et al. 1997). There is clear evidence that Shields was aware of this point, as he observed that both grain dimensions, shape and relative position are distributed properties and that, accordingly, the critical condition for each particle is a random variable. As a matter of fact, in his original dissertation Shields represented the critical zone on the $X-Y$ plane as a shaded area rather than a curve. It seems important to emphasise the strong stochastic component of even the simplest process in the field of sediment transport and we believe that this intrinsic stochastic nature should be taken into account in any formulation of equation (8). In this paper the attention will be focused on the inception of sediment transport in laminar and hydraulically smooth turbulent flow conditions. The analysis will be limited to the range $X<5$ approximately, as far as turbulent flow conditions are concerned. To this purpose, it should be observed that $X$ reflects the motion of the fluid around the grains of the bed rather than the motion of the fluid in a channel. Actually, it is easy to show that

$$
X=\frac{\operatorname{Re} v_{*}}{4 Z \bar{U}}
$$

and so there is not a one-to-one relationship between the grain Reynolds number $X$ and the stream Reynolds number, Re. However, by its definition, if one assumes that the characteristic linear dimension of the bed roughness is given by $\mathrm{D}$, only laminar and hydraulically smooth turbulent flows can be characterized by values $X<5$.

Over the last two decades, the experimental data obtained by several authors (Rees, 1966, Grass, 1970, White, 1970, Mantz, 1977, Yalin e Karahan, 1979) have shown an inconsistency in the traditionally accepted hyperbolic pattern for relation (8) in the field $X$ $<3$. Mantz (1977), integrating the data available in literature (Rees, 1966, White, 1970) with his own experimental measurements, proposed an extended Shields diagram in the range 0.03 $<X<1$, as a linear regression on the results of equation

$$
Y=\frac{0.1}{X^{\beta}}
$$

where $\beta=0.3$ substitutes the originally proposed $\beta=1$. Yalin and
Karahan (1979) have shown that expression (9) with $\beta=1$ is not supported by evidence. At the same time, the identified pattern is not explained by the value $\beta=0.3$ proposed by Mantz either. Noticeably, by comparing the data obtained in laminar conditions and those in turbulent conditions, these authors have hypothesized the existence of a bifurcation of the Shields curve in correspondence of the two regimes. Although the experimental points show a clear trend on the $X-Y$ plane, the authors do not propose any analytical relationship and do not come to a conclusion on the asymptotic behaviour of the critical curve as $X$ tends to zero.

Although these observations deeply question the use of the traditional Shields criterion in the range $X<1$, where it would cause an underestimation of the erosive process, they have apparently passed almost unnoticed. In fact it is not uncommon in literature to observe that the Shields curve is still used in its original form. There are several reasons for this misuse. On one hand, the original hyperbolic trend with $\beta=1$ has often been justified on the basis of dimensional and mechanical arguments. On the other hand, the $X$ range in question is specific for laminar and hydraulically smooth flow conditions. These situations, uncommon in the field of open channel hydraulics, are typical in the field of sheetflow erosion along hillslopes (e.g, Emmett, 1978, Zhang and Cundy, 1987). Possibly, further explanations may lie in the scarcity of experimental data in the range of low $X$ values and in the lack of a physical explanation for the observed pattern.

In this study a series of experiments is presented in order to widen the set of data available in the field $X<10$. The results confirm the existence of a bifurcation of the Shields curve for $X>2$, when turbulent and laminar flows potentially coexist for the same grain Reynolds number and suggest a trend of $Y_{c r}$ to a constant value for $X$ approaching zero. The laboratory observation of the process in a specifically designed flume, allows the formulation of a simple mechanical scheme that interprets the results and the observed trends within a statistical framework.

\section{Experimental equipment}

The experiments were carried out in the flume shown in Figure (1). The perspex flume that is $2 \mathrm{~m}$ long and $15 \mathrm{~cm}$ wide, is joined to the upstream tank with a hinged joint. The slope of the channel can be varied by operating the micrometer screw that governs the vertical position of the outlet, within a precision of $0.1 \mathrm{~mm}$. Accordingly, the error on the slope is bounded below $0.005 \%$.

The fluid is recirculated from the upper to the lower tank, while a set of filters inside the upper tank guarantee that the momentum of the incoming fluid is dissipated. In addition, these filters prevent the recirculation of the fine sediments used in the experiments. A properly shaped entrance lets the fluid enter the channel with no perceptible perturbations and with a velocity that is uniformly directed parallel to the channel axis. Approximately $0.7 \mathrm{~m}$ from the channel entrance, a $2 \mathrm{~cm}$ deep, $17 \times 5 \mathrm{~cm}^{2}$ cut-out has been put in the bottom, where the sediments are placed during the experiments.

The dimensions of the experimental apparatus have been established on the basis of low submergence flows, with maximum depth $<2 \mathrm{~cm}$. Accordingly, a sufficiently wide plane flow field 


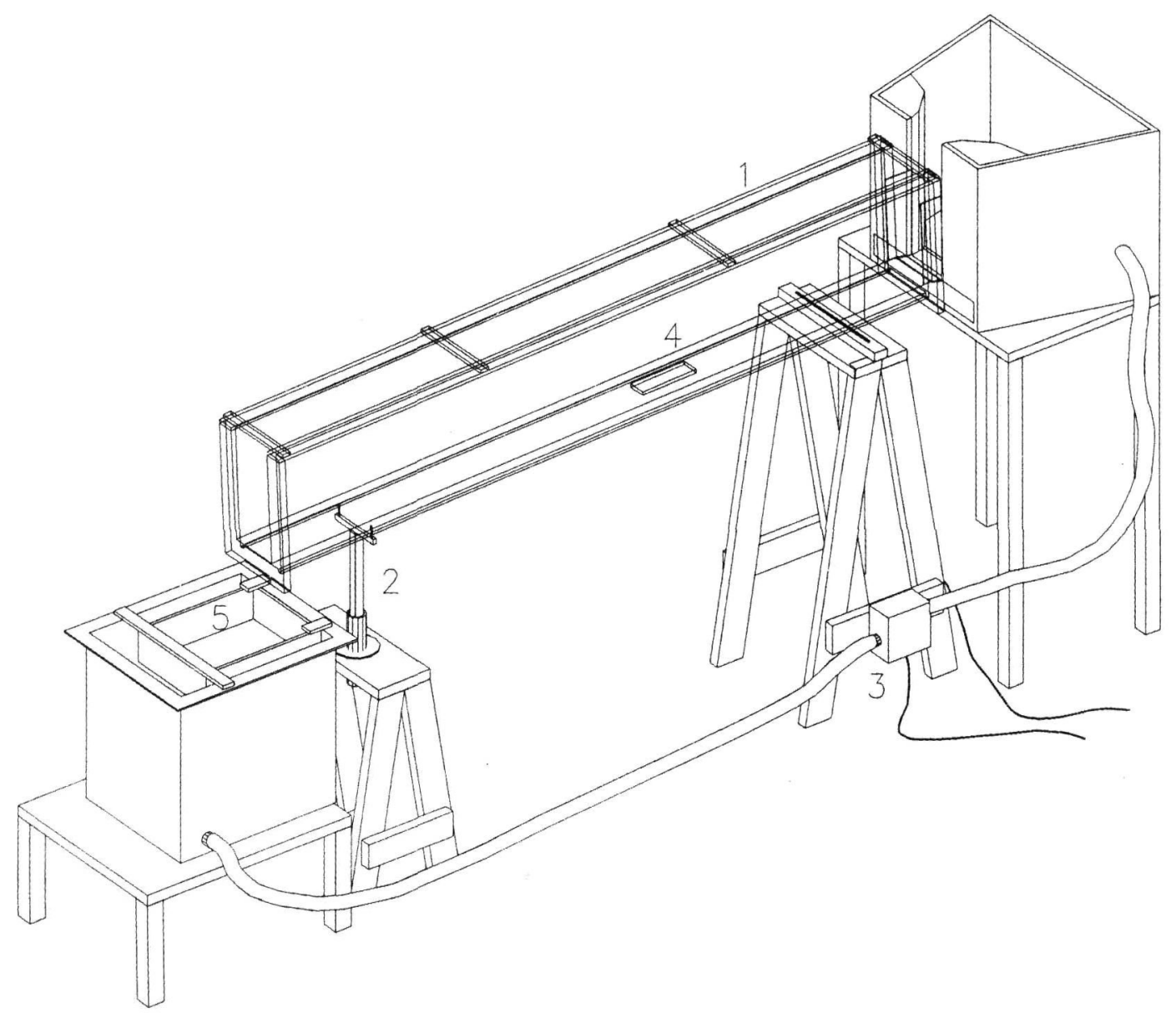

Fig. 1: The experimental apparatus. Please note the transparent perspex flume (1) with the flexible joint. Its slope is governed by a micrometer screw (2) and the ricirculating discharge between the upstream and downstram tanks is kept by the low-head pump (3). During the experiments for the determination of the inception of sediment transport, sediments are placed in the patch (4), cut on the bottom of the flume. These sediments are then collected in the sediment trap (5).

has always been guaranteed and the patch surface area was considered sufficiently representative of the investigated erosive processes. The mobilisation of grains on an incoherent bed is a consequence of the interaction of two stochastic fields. The first is the bottom shear stress distribution exerted by the flow and the second is the distribution of the critical tractive stresses that are needed to move a grain from its resting position on the bed. While the relative uniformity of the former field has been guaranteed by the steady flow fields considered in this contribution, the latter, that clearly reflects the bottom geometry (i.e. grain relative position and shape), is assured by the high values of the $A / D^{2}$ ratio maintained during all the experiments (where $A$ represents the patch area and $D$ the characteristic linear dimension of the sediment).

If we limit our attention to laminar flow fields, the adimensional variable $X$ can be easily expressed as a function of $Z$ and the stream Reynolds number $R e=4 U R / v$, (where $R[\mathrm{~m}]$ is the hydraulic radius),

$$
X=\frac{1}{Z}\left(\frac{3}{4} R e\right)^{0.5}
$$

Accordingly, low $X$ values can be explored only by operating on flows that are at the same time characterised by low $R e$ and high $Z$ values. In addition, it is essential that the adimensional shear stress $Y$ is kept sufficiently high to start sediment transport. Consequently, we used a fluid whose kinematic viscosity $v$ could be varied. Let us consider a constant $Q$ value. By increasing $v$ we obtain a decrease in $R e$ and a simultaneous increase in $Z$. In this situation, where $J$ is imposed by the channel slope, we have an increase in the average bottom shear stress $\tau_{0}=\gamma R J$. However, the main advantage is that, by changing the viscosity of an appropriately chosen fluid, a single sediment mixture could theoretically be used to explore the whole Shields plane. Accordingly, in the present work we have used water and a water-glucose solution, whose viscosity and density change with concentration. Starting from an initial weight dilution ratio of $40 \%$, we have measured values varying in the range of

$$
\begin{aligned}
& 998<\rho<1360 \mathrm{~kg} / \mathrm{m}^{3} \\
& 1.01 \cdot 10^{-06}<v<2.81 \cdot 10^{-04} \mathrm{~m}^{2} / \mathrm{s}
\end{aligned}
$$

at $T=20^{\circ} \mathrm{C}$. It is our understanding that this is the first time that 
a water-glucose solution has been used for hydraulic experimentation. Accordingly, the rheological behaviour of this fluid has been verified by using a microcomputer controlled dynamic stress rheometer. We studied the response of the fluid under a set of typical steady and transient tests (creep, stress ramp and dynamic frequency sweep), that demonstrated its newtonian behaviour in the whole range of stresses expected in the experiments.

The velocity profile, that can be regarded as approximately uniform at the entrance of the channel, is progressively modified due to the growth of the boundary layer. In order to obtain uniform stress distribution on the control area, the patch must not only be located beyond the point where the bottom-induced boundary layer is completely developed, but also out of the boundary layers caused by the walls. With the purpose of a uniform stress distribution on the control area, this must be located beyond the point where the bottom-induced boundary layer has come to a complete development, but, at the same time, out of the boundary layers caused by the walls.

The first condition has always been satisfied, due to the small value of the flow depth $h$, compared to the distance separating the channel inlet to the control area. The full development distance $x$ has been determined using Blasius's formula for the development of a laminar boundary layer on a smooth plate

$$
h=5 \begin{gathered}
x U \\
U_{\infty}
\end{gathered}
$$

where $U_{\infty}$, the upstream free-stream velocity, has been set equal to the average uniform flow velocity. The second condition requires a distinction on the basis of the viscosity values. Let us suppose we use equation (11) to obtain an approximate evaluation of the growth of the wall-induced boundary layer, as proposed by Yalin and Karahan (1979). If the experimental fluid is water, this growth turns out to be slow enough to confirm the above mentioned assumptions. However, with the fluid higher viscosity, i.e. the water-glucose solution, it is impossible to locate the control area in front of the zone influenced by the boundary layer without violating the first condition. Accordingly, we have verified a weaker condition, i.e. the location of the control area was located after the point of full development of the wall boundary layer. Clearly in this condition we have sacrificed the planarity of the flow field on the patch, in favour of the longitudinal uniformity of the bottom stress. However, as shown by typical fully developed velocity profile in the channel, the flow field in correspondence of the control area was practically plane.

At the beginning and at the end of each experiment, temperature, density and viscosity of the fluid have been recorded using, respectively: a digital thermometer, a set of floating densimeters and a suitably sized Ostwald viscometer. The flow depth has been monitored by using three micrometer screw gauges, two were placed immediately before and after the control area, while the third was placed $20 \mathrm{~cm}$ in front of the channel outlet cross $\mathrm{sec}$ tion. The measurements have shown that the influence of the upstream and downstream boundary conditions on the uniformity of the flow were negligible. Discharges (in the range of a few litres/minute), were measured volumetrically. The tractive action on the bed, computed as $\tau_{0}=\gamma R J$, has been increased by varying the flume slope. In this way, by keeping $Q$ constant during the experiment also the flow Reynolds number $R e$ is approximately constant. The laminarity of the flow field has also been verified with a methylene blue tracer injected in the flow at the end of each experiment. Table (1) reports properties of the granular materials used in the experiments.

\section{Description of the experiments and results}

Starting from the very beginning of each experiment, when the average shear velocity increases a progressive adjustment of the grains on the erodible patch was observed. This was largely due to the ballistic deposition of the surface. After this phase the erodible surface is 'water worked', and it reacts to a further increase in the shear stress with the detachment of several isolated grains on the patch that are transported downward by the stream. Neither of these situations has however been regarded as the inception of transport, that in our opinion can be observed quite sharply in the form of a progressive mobilisation of a substantial percentage of grains covering the bed. This phase is followed by a rapid collapse of the bottom. Accordingly, as observed also by other authors (e.g., Wang Sany-yi and Wen Shen Hsieh (1985), Yalin and Karahan (1979)), in laminar conditions the inception of sediment transport, although difficult to define in a quantitative way, is considerably less ambiguous than in turbulent conditions. These authors have described the mobilisation process as that of a grain carpet, a term portrayed by DuBoys (1879). In Table (2) and (3) the measured data are reported and split according to the flow regime. The data are then shown on the Shields $X$ - $Y$ plane in Figure (2) and (3).

\section{Analysis and interpretation of the results}

As already observed by other authors, and confirmed by our experimentation, the original relation (9), where $\beta=1$, is not applicable. If one compares the experimental data with the trend shown by the Shields curve for $X>1$, the hypothesis advanced by Yalin and Karahan (1978) regarding the existence of a separate curve

Table 1: Granular materials used in the experiments.

\begin{tabular}{|c|c|c|c|c|c|}
\hline MATERIAL & $\begin{array}{c}\rho \\
{\left[\mathrm{kg} / \mathrm{m}^{3}\right]}\end{array}$ & $\begin{array}{l}\text { GRANULOMETRY } \\
(D \text {, in } \mathbf{~ m m})\end{array}$ & DESCRIPTION & $\mathbf{D}_{90} / \mathbf{D}_{30}$ & $\begin{array}{c}\text { ASTM } \\
\text { CLASSIFICATION }\end{array}$ \\
\hline A & 2600 & 0.08 & marble powder & 2.3 & $\begin{array}{l}\text { sand } 71 \% \\
\text { clay - silt } 29 \%\end{array}$ \\
\hline B & 2800 & $2-4$ & $\begin{array}{l}\text { water worked } \\
\text { limestone }\end{array}$ & & \\
\hline C & 2440 & $0.1-0.25$ & $\begin{array}{l}\text { water worked } \\
\text { quartzite }\end{array}$ & & \\
\hline D & 2460 & 0.0001 & sylica & & \\
\hline $\mathrm{D}_{1}$ & & $0.177-0.250$ & microsphere & & \\
\hline $\mathrm{D}_{2}$ & & $0.250-0.4$ & & & \\
\hline $\begin{array}{l}D_{3} \\
D_{4}\end{array}$ & & $\begin{array}{l}2 \\
3\end{array}$ & & & \\
\hline$E_{1}$ & 2570 & 1.25 & sand & 1.8 & sand $100 \%$ \\
\hline$E_{2}$ & 2570 & 0.8 & sand & 1.9 & sand $100 \%$ \\
\hline $\mathrm{E}_{3}$ & 2570 & 1.6 & sand & 3 & $\begin{array}{l}\text { small gravel } 30 \% \\
\text { sand } 70 \%\end{array}$ \\
\hline $\mathrm{E}_{4}$ & 2570 & 3 & sand & & \\
\hline G & 2530 & $0.4-0.6$ & sand & & \\
\hline $\mathrm{G}_{1}$ & 2530 & 0.25 & & 1.8 & $\begin{array}{l}\text { sand } 99 \% \\
\text { clay - silt } 1 \%\end{array}$ \\
\hline
\end{tabular}


Table 2: results for the experiments in laminar regime (w=water; $g=w a t e r-g l u c o s e ~ s o l u t i o n)$

\begin{tabular}{|c|c|c|c|c|c|c|c|c|c|c|c|c|c|c|c|c|c|}
\hline fluid & $\begin{array}{c}T \\
{\left[{ }^{\circ} \mathrm{C}\right]}\end{array}$ & $\begin{array}{c}D \\
{[\mathrm{~m}]}\end{array}$ & $\begin{array}{c}\rho \text { sed. } \\
{\left[\mathrm{Kg} / \mathrm{m}^{3}\right]}\end{array}$ & $\stackrel{v}{\left[m^{2} / s\right]}$ & $\begin{array}{c}\rho \text { fluid } \\
{\left[\mathrm{Kg} / \mathrm{m}^{3}\right]}\end{array}$ & $\begin{array}{l}\mathrm{sg} \\
\mathrm{I} \cdot \mathrm{I}\end{array}$ & $\begin{array}{c}h \\
\text { [m] }\end{array}$ & $\begin{array}{c}\mathbf{R} \\
{[\mathrm{m}]}\end{array}$ & J.] & $\underset{[\mathrm{m} / \mathrm{s}]}{v^{\bullet}}$ & $\begin{array}{c}a \\
{[1 / \mathrm{min}]}\end{array}$ & $\underset{[\mathrm{m} / \mathrm{s}]}{U}$ & $\begin{array}{c}x \\
{[-1}\end{array}$ & $\begin{array}{c}y \\
H-1\end{array}$ & $\begin{array}{c}2 \\
{[-1}\end{array}$ & $\begin{array}{l}\mathrm{Re} \\
\mathrm{H} \cdot \mathrm{I}\end{array}$ & $\mathrm{F}$ \\
\hline$w$ & 21 & 0.000250 & 2530 & $9.85 \mathrm{E}-07$ & 998 & 1.54 & 0.0018 & 0.0018 & 0.0280 & 0.0209 & 2.99 & 0.204 & 5.18 & 0.12 & 8.52 & 1321.81 & 1.61 \\
\hline$w$ & 21 & 0.000250 & 2530 & 9.85E-07 & 998 & 1.54 & 0.0018 & 0.0016 & 0.0270 & 0.0204 & 2.70 & 0.188 & 5.04 & 0.11 & 8.40 & 1192.83 & 1.50 \\
\hline$w$ & 20 & 0.000335 & 2460 & $1.01 E-06$ & 998 & 1.46 & 0.0018 & 0.0018 & 0.0355 & 0.0234 & 4.37 & 0.303 & 7.75 & 0.11 & 4.78 & 1882.83 & 2.42 \\
\hline$w$ & 21 & 0.000335 & 2460 & $9.85 \mathrm{E}-07$ & 998 & 1.48 & 0.0021 & 0.0021 & 0.0140 & 0.0168 & 3.82 & 0.201 & 5.57 & 0.08 & 8.30 & 1677.65 & 1.40 \\
\hline$w$ & 21 & 0.000500 & 2530 & $9.85 E-07$ & 998 & 1.54 & 0.0019 & 0.0019 & 0.0230 & 0.0204 & 4.80 & 0.269 & 10.12 & 0.08 & 3.80 & 2024.25 & 1.97 \\
\hline$w$ & 22 & 0.000800 & 2570 & $9.82 E-07$ & 998 & 1.58 & 0.0017 & 0.0017 & 0.0365 & 0.0244 & 4.50 & 0.294 & 19.32 & 0.05 & 2.13 & 2032.92 & 2.28 \\
\hline$w$ & 21.5 & 0.000335 & 2460 & $9.73 \mathrm{E}-07$ & 998 & 1.46 & 0.0010 & 0.0016 & 0.0365 & 0.0237 & 4.37 & 0.303 & 8.15 & 0.12 & 4.78 & 1954.42 & 2.42 \\
\hline$w$ & 21 & 0.000800 & 2570 & 9.85E-07 & 998 & 1.58 & 0.0017 & 0.0017 & 0.0365 & 0.0244 & 4.5 & 0.294 & 19.81 & 0.05 & 2.13 & 1985.45 & 2.28 \\
\hline$w$ & 19 & 0.000335 & 2460 & $1.01 \mathrm{E} .06$ & 998 & 1.46 & 0.0018 & 0.0018 & 0.0280 & 0.0220 & 2.5 & 0.154 & 7.29 & 0.10 & 5.37 & 1074.33 & 1.16 \\
\hline$w$ & 21 & 0.000180 & 2440 & $9.85 \mathrm{E}-07$ & 998 & 1.44 & 0.0024 & 0.0023 & 0.0160 & 0.0191 & 4.23 & 0.196 & 3.49 & 0.14 & 13.33 & 1849.45 & 1.28 \\
\hline$w$ & 21 & 0.001250 & 2570 & 9.85E.07 & 998 & 1.58 & 0.0017 & 0.0017 & 0.0770 & 0.0354 & 2.2 & 0.144 & 44.96 & 0.07 & 1.36 & 970.67 & 1.11 \\
\hline$w$ & 21 & 0.002000 & 2460 & $9.85 E-07$ & 998 & 1.46 & 0.0010 & 0.0010 & 0.0575 & 0.0241 & 4.46 & 0.476 & 48.83 & 0.02 & 0.52 & 1984.88 & 4.72 \\
\hline$h w$ & 38.2 & 0.000350 & 2530 & $6.87 \mathrm{E} \cdot 07$ & 998 & 1.54 & 0.0014 & 0.0014 & 0.0400 & 0.0232 & 2.4 & 0.190 & 11.83 & 0.10 & 4.00 & 1524.19 & 1.63 \\
\hline hw & 44.2 & 0.000180 & 2440 & 6.15E-07 & 998 & 1.44 & 0.0015 & 0.0015 & 0.0260 & 0.0194 & 2.2 & 0.163 & 5.87 & 0.15 & 8.33 & 1558.71 & 1.34 \\
\hline$h w$ & 43.4 & 0.000800 & 2570 & $6.27 \mathrm{E} .07$ & 998 & 1.58 & 0.0016 & 0.0018 & 0.0320 & 0.0222 & 2.7 & 0.188 & 28.29 & 0.04 & 2.00 & 1873.90 & 1.50 \\
\hline 2 & 17.5 & 0.000250 & 2530 & 3.00E.05 & 1280 & 0.98 & 0.0104 & 0.0091 & 0.0055 & 0.0222 & 5 & 0.053 & 0.18 & 0.21 & 41.60 & 65.05 & 0.17 \\
\hline 8 & 17.5 & 0.002000 & 2460 & $3.00 \mathrm{E}-05$ & 1280 & 0.92 & 0.0083 & 0.0075 & 0.0280 & 0.0453 & 10 & 0.134 & 3.02 & 0.11 & 4.15 & 133.39 & 0.47 \\
\hline 8 & 18.5 & 0.001250 & 2570 & 3.00E.05 & 1280 & 1.01 & 0.0059 & 0.0054 & 0.0340 & 0.0425 & 5 & 0.095 & 1.77 & 0.15 & 4.68 & 68.71 & 0.40 \\
\hline 8 & 19 & 0.000170 & 2440 & $3.18 \mathrm{E}-05$ & 1280 & 0.91 & 0.0075 & 0.0068 & 0.0045 & 0.0173 & 1.25 & 0.019 & 0.09 & 0.20 & 44.12 & 15.88 & 0.07 \\
\hline 9 & 19.5 & 0.000250 & 2530 & $3.18 \mathrm{E}-05$ & 1280 & 0.98 & 0.0068 & 0.0080 & 0.0080 & 0.0217 & 1.6 & 0.027 & 0.17 & 0.20 & 26.20 & 20.57 & 0.11 \\
\hline 8 & 21 & 0.003000 & 2460 & $3.00 \mathrm{E} .05$ & 1280 & 0.92 & 0.0082 & 0.0057 & 0.0570 & 0.0586 & 10 & 0.179 & 5.68 & 0.12 & 2.07 & 138.84 & 0.73 \\
\hline 2 & 20 & 0.000800 & 2570 & $3.73 E-05$ & 1280 & 1.01 & 0.0074 & 0.0067 & 0.0135 & 0.0298 & 3.75 & 0.057 & 0.84 & 0.11 & 9.19 & 40.73 & 0.21 \\
\hline 8 & 19.4 & 0.000800 & 2570 & $4.00 E .05$ & 1280 & 1.01 & 0.0084 & 0.0075 & 0.0130 & 0.0309 & 4.4 & 0.059 & 0.62 & 0.12 & 10.44 & 43.89 & 0.20 \\
\hline 2 & 20.2 & 0.000080 & 2800 & $5.55 E .05$ & 1295 & 1.01 & 0.0126 & 0.0108 & 0.0020 & 0.0145 & 2.3 & 0.020 & 0.02 & 0.27 & 156.88 & 15.78 & 0.00 \\
\hline 2 & 19.4 & 0.000080 & 2800 & 5.93E-05 & 1295 & 1.01 & 0.0088 & 0.0002 & 0.0034 & 0.0144 & 0.57 & 0.009 & 0.02 & 0.28 & 85.00 & 3.92 & 0.04 \\
\hline 8 & 19.9 & 0.000250 & 2530 & $5.87 E-05$ & 1295 & 0.95 & 0.0087 & 0.0078 & 0.0047 & 0.0188 & 1.52 & 0.020 & 0.08 & 0.15 & 34.60 & 10.32 & 0.07 \\
\hline 2 & 19.8 & 0.001250 & 2570 & $5.87 \mathrm{E} \cdot 05$ & 1295 & 0.98 & 0.0070 & 0.0084 & 0.0240 & 0.0388 & 3.5 & 0.058 & 0.83 & 0.12 & 5.60 & 24.24 & 0.21 \\
\hline 2 & 23.7 & 0.00025 & 2530 & $1.95 \mathrm{E} .04$ & 1340 & 0.8881 & 0.0107 & 0.0094 & 0.0050 & 0.0214 & 1.12 & 0.012 & 0.03 & 0.21 & 42.80 & 2.23 & 0.04 \\
\hline 2 & 21.7 & 0.001250 & 2570 & $3.18 E-04$ & 1360 & 0.8897 & 0.0055 & 0.0051 & 0.0390 & 0.0443 & 0.566 & 0.011 & 0.17 & 0.18 & 4.40 & 0.74 & 0.05 \\
\hline 2 & 22.8 & 0.000800 & 2570 & $2.81 \mathrm{E} .04$ & $13 B 0$ & 0.8897 & 0.0051 & 0.0048 & 0.0180 & 0.0290 & 0.25 & 0.005 & 0.08 & 0.12 & 8.38 & 0.37 & 0.02 \\
\hline 9 & 22.8 & 0.00025 & 2530 & $2.81 \mathrm{E}-04$ & 1360 & 0.8603 & 0.0089 & 0.0083 & 0.0095 & 0.0243 & 0.26 & 0.004 & 0.02 & 0.28 & 27.60 & 0.38 & 0.02 \\
\hline
\end{tabular}

Table 3: results for the experiments in smooth turbulent regime ( $\mathrm{w}, \mathrm{hw}=\mathrm{water})$.

\begin{tabular}{|c|c|c|c|c|c|c|c|c|c|c|c|c|c|c|c|c|c|}
\hline mild & $\begin{array}{c}\top \\
{\left[{ }^{\circ} \mathrm{C}\right]}\end{array}$ & $\begin{array}{c}D \\
{[\mathrm{~m}]}\end{array}$ & $\begin{array}{l}\rho \text { sod. } \\
{\left[\mathrm{Kg} / \mathrm{m}^{3}\right]}\end{array}$ & $\stackrel{\nu}{\left[m^{2} / s\right]}$ & $\begin{array}{l}\rho \text { fhid } \\
{\left[\mathrm{Kg} / \mathrm{m}^{3}\right]}\end{array}$ & $\begin{array}{l}\mathbf{S g} \\
H\end{array}$ & $\begin{array}{c}h \\
{[m]}\end{array}$ & $\stackrel{k}{k}$ & $\vec{H}$ & $\underset{[m / s]}{v 0}$ & $\begin{array}{c}a \\
{[1 / \mathrm{min}]}\end{array}$ & $\underset{[\mathrm{m} / \mathrm{s}]}{U}$ & $\begin{array}{c}x \\
1.1\end{array}$ & $\begin{array}{c}Y \\
1.1\end{array}$ & 2 & $\begin{array}{l}\text { Re } \\
\text { [-] }\end{array}$ & $\begin{array}{l}f . \\
1.1\end{array}$ \\
\hline$w$ & 21 & 0.00009 & 2460 & $9.85 \mathrm{E}-07$ & 998 & 1.48 & 0.0028 & 0.0025 & 0.0125 & 0.0176 & 8.34 & 0.271 & 1.80 & 0.24 & 28.89 & 2765.5 & 1.70 \\
\hline$w$ & 22 & 0.00080 & 2570 & $9.62 \mathrm{E}-07$ & 998 & 1.58 & 0.0023 & 0.0022 & 0.0235 & 0.0227 & 8.00 & 0.290 & 18.86 & 0.04 & 2.88 & 2689.5 & 1.93 \\
\hline$w$ & 21 & 0.00200 & 2480 & $9.85 \mathrm{E}-07$ & 998 & 1.46 & 0.0018 & 0.0017 & 0.0420 & 0.0265 & 6.56 & 0.418 & 53.89 & 0.02 & 0.88 & 2891.7 & 3.18 \\
\hline$w$ & 21 & 0.00200 & 2460 & $9.85 \mathrm{E}-07$ & 998 & 1.46 & 0.0017 & 0.0016 & 0.0425 & 0.0262 & 5.88 & 0.389 & 53.13 & 0.02 & 0.84 & 2595.7 & 3.03 \\
\hline$w$ & 21 & 0.00200 & 2460 & $9.85 \mathrm{E}-07$ & 998 & 1.48 & 0.0018 & 0.0017 & 0.0415 & 0.0264 & 8.49 & 0.412 & 53.56 & 0.02 & 0.88 & 2861.2 & 3.15 \\
\hline$w$ & 22 & 0.000800 & 2570 & $9.62 \mathrm{E}-07$ & 998 & 1.58 & 0.0023 & 0.0022 & 0.0235 & 0.0226 & 6 & 0.293 & 18.76 & 0.04 & 2.84 & 2690.4 & 1.96 \\
\hline$w$ & 20 & 0.000250 & 2530 & $1.01 \mathrm{E}-08$ & 998 & 1.54 & 0.0024 & 0.0023 & 0.0210 & 0.0217 & 8.6 & 0.312 & 5.38 & 0.12 & 9.40 & 2816.1 & 2.06 \\
\hline$w$ & 21.5 & 0.003000 & 2570 & $9.02 \mathrm{E}-07$ & 998 & 1.58 & 0.0019 & 0.0019 & 0.0570 & 0.0322 & 8.5 & 0.380 & 100.37 & 0.02 & 0.83 & 2928.8 & 2.78 \\
\hline$w$ & 18 & 0.000800 & 2570 & $1.04 \mathrm{E}-08$ & 998 & 1.58 & 0.0018 & 0.0018 & 0.0340 & 0.0242 & 6 & 0.370 & 18.62 & 0.05 & 2.25 & 2504.0 & 2.79 \\
\hline$h w$ & 40 & 0.003000 & 2460 & $8.62 \mathrm{E}-07$ & 998 & 1.46 & 0.0017 & 0.0010 & 0.0870 & 0.0371 & 5.38 & 0.382 & 168.19 & 0.03 & 0.55 & 3534.2 & 2.85 \\
\hline$h w$ & 44 & 0.000500 & 2530 & $8.15 \mathrm{E}-07$ & 998 & 1.54 & 0.0018 & 0.0018 & 0.0265 & 0.0214 & 3.8 & 0.222 & 17.38 & 0.08 & 3.60 & 2540.7 & 1.07 \\
\hline$w$ & 21 & 0.00008 & 2600 & $9.85 \mathrm{E}-07$ & 998 & 1.89 & 0.0024 & 0.0023 & 0.0125 & 0.0188 & 4.91 & 0.229 & 1.37 & 0.22 & 29.75 & 2145.2 & 1.50 \\
\hline$w$ & 20 & 0.00034 & 2480 & $1.01 \mathrm{E}-0 \mathrm{~B}$ & 998 & 1.48 & 0.0025 & 0.0024 & 0.0200 & 0.0218 & 5.40 & 0.240 & 7.22 & 0.10 & 7.48 & 2299.6 & 1.53 \\
\hline$w$ & 21 & 0.00125 & 2570 & $9.85 \mathrm{E}-07$ & 998 & 1.58 & 0.0017 & 0.0017 & 0.0340 & 0.0235 & 4.74 & 0.310 & 29.88 & 0.03 & 1.38 & 2092.7 & 2.40 \\
\hline$w$ & 22 & 0.000335 & 2460 & $9.62 \mathrm{E}-07$ & 998 & 1.46 & 0.0025 & 0.0024 & 0.0195 & 0.0215 & 5.4 & 0.240 & 7.49 & 0.10 & 7.48 & 2414.3 & 1.53 \\
\hline$w$ & 20 & 0.000500 & 2530 & $1.01 \mathrm{E} .08$ & 998 & 1.54 & 0.0020 & 0.0019 & 0.0250 & 0.0219 & 4.8 & 0.287 & 10.82 & 0.08 & 4.00 & 2057.3 & 1.90 \\
\hline$w$ & 20 & 0.000500 & 2530 & $1.01 \mathrm{E}-06$ & 998 & 1.54 & 0.0022 & 0.0021 & 0.0255 & 0.0229 & 5.6 & 0.289 & 11.32 & 0.07 & 4.30 & 2395.6 & 1.99 \\
\hline$w$ & 21.5 & 0.003000 & 2480 & $9.62 \mathrm{E}-07$ & 998 & 1.48 & 0.0010 & 0.0016 & 0.0730 & 0.0335 & 5.7 & 0.396 & 104.43 & 0.03 & 0.53 & 2578.4 & 3.16 \\
\hline$w$ & 18.5 & 0.000250 & 2530 & $1.05 \mathrm{E} .08$ & 998 & 1.54 & 0.0021 & 0.0020 & 0.0255 & 0.0226 & 4.7 & 0.249 & 5.38 & 0.14 & 8.40 & 1935.2 & 1.73 \\
\hline & 25.8 & 0.002000 & 2480 & $8.98 \mathrm{E}-07$ & 998 & 1.46 & 0.0018 & 0.0018 & 0.0480 & 0.0288 & 5.5 & 0.840 & 64.06 & 0.03 & 0.90 & 2858.3 & 2.58 \\
\hline
\end{tabular}

for the inception of sediment transport in the laminar regime is confirmed. On the other hand, although we have strived to use the same criteria to identify the beginning of the transport, the experimental data do not follow a precisely identifiable curve. Rather, they group along a band, as can be observed also in the data proposed by other researchers (e.g., White, 1970).

Let us now consider the experimental evidence within a simple interpretative scheme. To begin with we observe that if one considers a pile of non-cohesive granular material, the grains that lie at its surface are mobilised when the surface is tilted just a few degrees beyond the mass angle of repose of the material. The mobilisation process that can be observed in this case, basically involves only an upper layer of the pile, not the overall pile. Accordingly, this situation seems to match what is observed in the hydraulics of sediment transport and can be represented on the Shields diagram as a straight line of equation $Y=A \tan (\Phi)$, where $A$ is a constant and $\Phi$ is the mass angle of repose of the granular mixture in submerged conditions. This equation, that reflects granular bed characteristics, clearly shows that there is an upper limit to $Y_{c r}$, whatever the hydrodynamic condition. Accordingly, a fortiori equations (9) cannot be asymptotically valid since the threshold represented on the Shields diagram does not correspond to the above mentioned overall mobilisation but to a lower conventional degree of movement.

A second experimental consideration is that the mobilisation process of the grains certainly does not support process interpretation based on a destabilising role of the lift force. Although this is in contrast with the mechanics adopted by other authors, the observed inception of grain motion in laminar regimes in our experimentation has never happened with a mechanism different from rolling or sliding. Thus the typical condition postulated for turbulent flow conditions, $L / w \geq 1$, where $L$ is the lift on a typical grain and $w$ the submerged weight, does not seem to hold for the hydrodynamic conditions explored in our experimentation. In our opinion, the mechanics implied by this relation is in contrast with the very observations of Yalin and Karahan, where they describe the inception of sediment transport in laminar flow with a carpet motion. In point of fact, by using the global momentum equation applied to a suitably chosen control volume and considering the mobilisation process for all the upper layer, there is no room for a net lift force acting on the bottom, whatever its direction. This is substantiated also by results obtained by several authors 


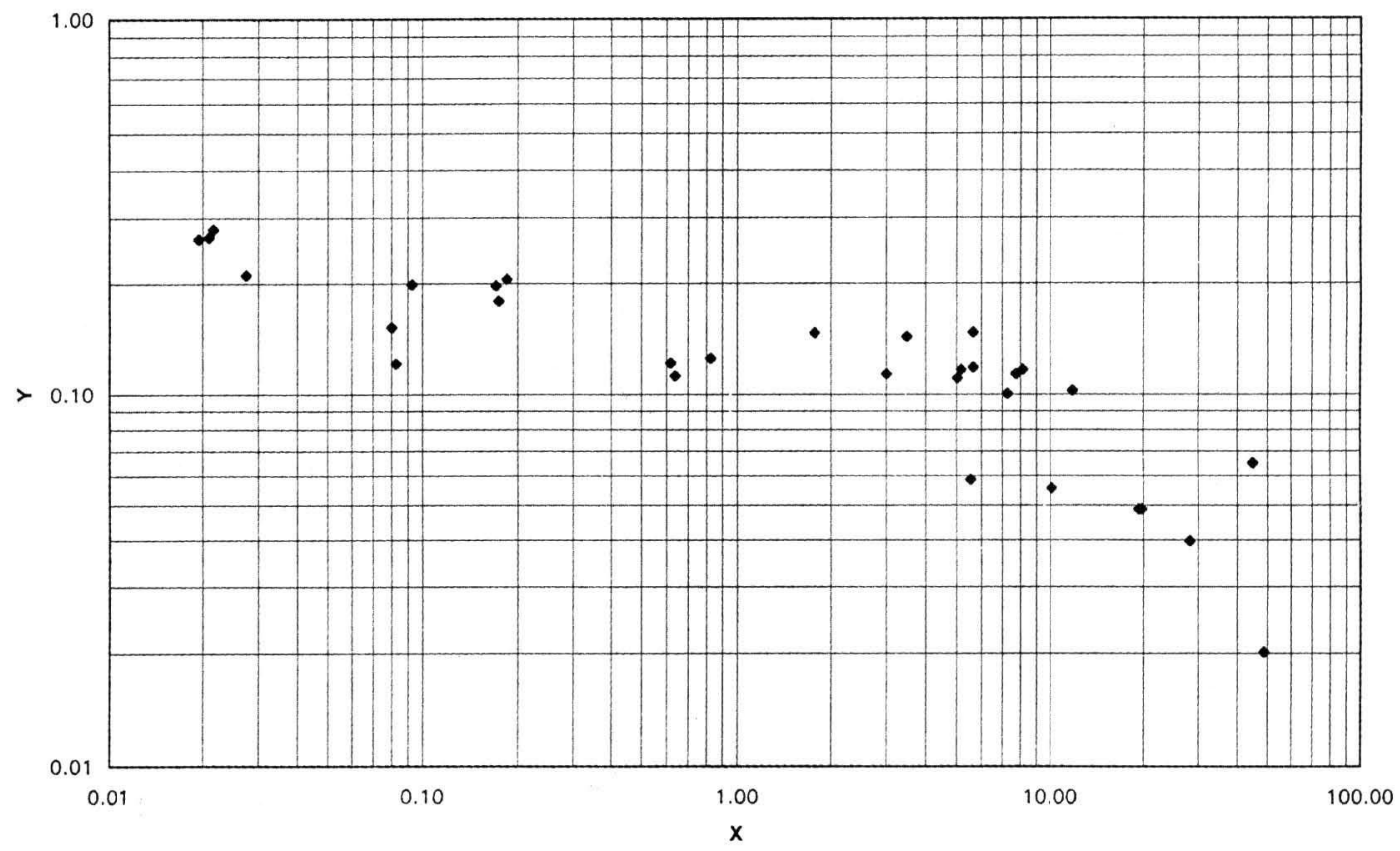

Figure 2: the results of the measurement in laminar flows on the Shields graph.

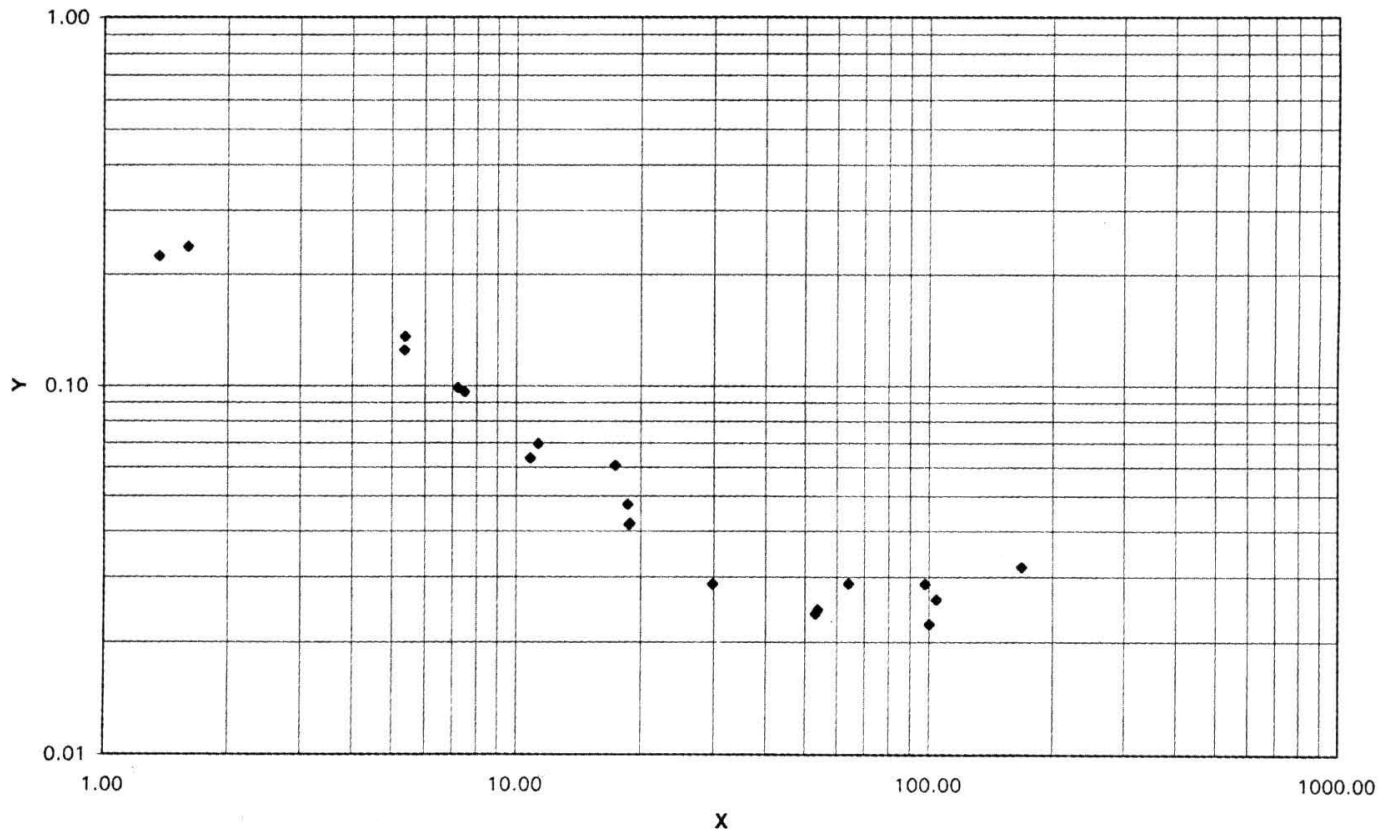

Figure 3: the results of the measurement in turbulent flows on the Shields graph.

(Coleman, 1967, Watters and Rao, 1971, Davies and Samad, 1978), who after studying single spheres on rough and smooth flume bottoms have often found stabilising lift forces.

In the remaining part of this contribution the inception of sediment transport will be interpreted only in terms of drag forces acting on the bottom. The drag force acting on a grain can be written as

$$
F_{t} \equiv F_{D}=\frac{1}{2} C_{D}(R e) \rho S U_{r e f}^{2}
$$

where $C_{D}$ is the drag coefficient for a grain, $R e$ is now the grain
Reynolds number defined using $U_{R e f}$ as a characteristic stream velocity in proximity of the bed and $S$ is the area of the exposed cross section of the grain.

Provided a sufficient sphericity for the grains, it is possible to suppose that the dependence of the drag coefficient on the Reynolds number is akin to that valid for an isolated grain invested by a uniform, infinitely wide, velocity profile. Under this hypothesis, we may use a relation for $C_{D}$ similar to that proposed by White [1974], that provides a good approximation (in the range $R e<100$ ) of the experimental data for an isolated sphere invested by a uniform flow 


$$
C_{D}(R e)=\frac{a}{R e}+\frac{b}{1+\sqrt{\operatorname{Re}}}+d
$$

and where $a, b, d$ are constants, whose values are, according to White, $a=24$ (following Stokes's solution), $b=6$ and $d=0.4$. In the range $0.4<\operatorname{Re}<64$ this relationship provides a drag coefficient that does not differ more than $25 \%$ than that measured for natural grains (e.g., Swamee e Ojha, 1991), with shape factor $\beta=e /(f g)^{0.5}$, $0.9<\beta<0.6$, being $g, f$ and $e$ the lengths of the three principal axes of the grain, in decreasing order. From hereon we shall disregard $d$ in (13), since it represents the asymptotic value of $C_{D}$ when the skin friction is negligible.

The value of $a$, derived from the theoretical Stokes solution for creeping flow, will be corrected as proposed by McNown (1951), to take into account the confinement of the flow induced by the presence of the bed

$$
a=24\left(1+0.562 \begin{array}{c}
D / 2 \\
s
\end{array}\right)
$$

where $s$ is the distance of the centre of the sphere of diameter $D$ from the wall. Presumably the presence of the bed will increase $b$ as well and tentatively we can apply the same correction factor

$$
b=6\left(1+0.562 \frac{D / 2}{s}\right) .
$$

As customary, the characteristic velocity is evaluated at distance $\mathrm{y}$ from the bed

$$
U_{r e f}=u\left(y_{r e f}\right)
$$

by using the linearised adimensional parabolic velocity profile valid in our experiments

$$
\frac{u(y)}{v_{*}}=\frac{v_{*} y}{v}
$$

\section{Considering that}

$$
X=\frac{v_{*} D}{v}=\operatorname{Re} \frac{v_{*}}{u\left(y_{\text {ref }}\right)}
$$

relation (12) can be rewritten as

$$
F_{D}(X)={ }_{2}^{1} \rho D_{4}^{2} v_{*}^{2}\left(\begin{array}{c}
v_{*} y_{\text {ref }} \\
v
\end{array}\right)^{2}\left(\begin{array}{c}
a \\
X \begin{array}{c}
v_{*} y_{\text {ref }} \\
v
\end{array}+\frac{b}{v_{*} y_{\text {ref }}} \\
\nu
\end{array}\right)
$$

where the reference height is proportional to diameter $D$

$$
y_{\text {ref }}=\alpha D
$$

being usually assumed in literature that $\alpha$ ranges between 0 and 1 .

As customary in the field of sediment transport, the stability of a single grain can be derived by a torque balance in critical conditions of spherically shaped grains; we may write:

$$
\frac{F_{D}}{w}=\operatorname{tg}(\varphi)\left(\cos (\psi)-\frac{\sin (\psi)}{\operatorname{tg}(\varphi)}\right)
$$

where $\psi$ is the angle of the bottom with respect to a horizontal surface, $\varphi$ is the rest angle for the grain. Accordingly, if we disregard the weight component in the direction of flow, the ratio (20) between the tractive force and the stabilising one, $F_{D} / w$ can be written as

$$
\begin{aligned}
\operatorname{tg}(\varphi) & =\frac{F_{D}(X)}{w} \\
& =\frac{\frac{1}{8} \rho \pi D^{2} v_{*}^{2}\left(\frac{v_{*} \alpha D}{v}\right)^{2}}{\frac{\pi D^{3}}{6} \gamma_{s}}\left(\frac{a}{X \frac{v_{*} \alpha D}{v}}+\frac{b}{1+\sqrt{X \frac{v_{*} \alpha D}{v}}}\right)
\end{aligned}
$$

It is then straightforward to obtain the relation

$$
Y=\frac{4 \operatorname{tg}(\varphi)}{3 \alpha}\left[\begin{array}{cc}
\alpha \\
\left.a+\alpha X^{2}\left(\begin{array}{cc}
b \\
1+X & \alpha
\end{array}\right)\right]
\end{array}\right.
$$

between the adimensional variables $X$ and $Y$ in critical conditions, for a single grain.

The course from a condition valid for a single grain to that valid for the erodible bed is achieved considering that the parameters $a, b, \alpha$ and $\operatorname{tg}(\varphi)$ are random variables, with a corresponding probability distributions that clearly depends on $X$ and that could be obtained only via a Montecarlo technique, based on the numerical simulation of the flow field over the bed. Without this piece of information we shall suppose, as far as $a$ and $b$ are concerned, that $s=D / 2$ in (14a) and (14b) (sphere resting on the bed), obtaining $a=37.49$ and $b=9.37$. Moreover, we shall assume $\alpha=0.16$, a value close to that proposed by other authors (e.g, Ikeda, 1982). The only parameter whose probability distribution, to our knowledge, has been experimentally investigated is the angle of repose $\varphi$ of a single grain, that is fixed until the bed is mobile. Kirchner et. al (1990) have studied the variability of the repose angle for a single grain resting on granular beds. Their work involved ballistically deposed and water-worked beds whose final configurations were fixed using a cyanoacrylate-based glue. The angle of repose for a single grain has been measured by randomly placing the test grain on the bottom in dry conditions and tilting it until the grain moves from its original resting position. The results show that the variability of $\varphi$ is so high that it cannot be properly represented by a single value, as confirmed also by numerical experiments that we have performed with synthetically generated granular 
beds (see Figure 4). Eventually, Kirchner et. al (1990) have proposed a cumulative probability distribution for the angle of repose of a grain of dimension $D$ settled on a bed whose median grain size is $D_{50}$, in the form

$$
\varphi_{n}=(30+0.5 n)\left(\begin{array}{c}
D \\
D_{50}
\end{array}\right)^{-0.3}
$$

where $\varphi_{n}$ is the $n$th percentile friction angle. Although equation (23) clearly shows that, when $D / D_{50}<1, \varphi$ may exceed $90^{\circ}$, the strong variability exhibited by the repose angle has almost totally been neglected in literature. It is likely that this is a consequence of the plane schematization widely used to represent granular beds, that greatly simplifies the geometry of the granular bed (e.g, see Figure 4) and, consequently, also the relative position between the grains.

Since all the sediments used during the experiments were characterized by quite uniform grading curves (as assumed in the original Shields' experiments), we can approximate (23) as

$$
\varphi_{n}=(30+0.5 n)
$$

Accordingly, relation (22) is rewritten as


(b)



(c)

Figure 4: examples of 3-D and 2-D sinthetically generated granular beds, obtained by ballistic deposition of uniformly distributed circular and spherical grains on a plane bottom. Figure (a) and (b) are a plan and side view of a bed of spherical uniform grains. The white grains in Figure (a) are the uppermost grain layer, in the sense of Yalin (1977). They can be removed from their positions without requiring any change in the surrounding configuration. While the grain repose angle of the cylinders in Figure (c) is $30^{\circ}$ due to their casual but regular arrangement, the measured repose angle for the randomly deposed bed of Figure (b) ranges between $8^{\circ}$ and $85^{\circ}$.

$$
Y_{n}=\frac{8.3 \operatorname{tg}(30+0.5 n)}{\left[37.5+\frac{1.5 X^{2}}{1+0.4 X}\right]}
$$

where $Y_{n}$ is the nth percentile $Y_{c r}$ value.

This relationship is shown in Figure (5), for the 10th, 20th and 30 th percentiles (corresponding respectively to friction angles of $35^{\circ}, 40^{\circ}$ and $45^{\circ}$ ), and reasonably coincides with the observed inception of sediment transport.

In conclusion, we note that the measured data, complemented with those from the literature, do not line-up along a precise curve. Rather, they define a band that is agreeably described by relation (25). This relation explains the trend towards a constant value of the adimensional tractive force when $X$ tends to 0 , as supposed by White (1940) on the basis of very few data and as suggested by Narayanan (1980). Moreover, it shows that the pattern of the experimental data is distinct from that measured in turbulent conditions, in the range $X>2$.

\section{Conclusions}

In this contribution we consider the identification of the inception of sediment transport in viscous dominated flow, broadening the data already available in literature with a set of experiments in laminar and hydraulically smooth turbulent conditions. The experimental data measured in this research cover a range approximately $0.019 \leq X \leq 50$. Bearing in mind the range of viscosity, the lowest values of $X$ have been obtained by operating with the sediments characterised by the minimum characteristic linear dimension. The difficulty in observing the movement of these sediments on the control area could have possibly led to a slight overestimation of the critical tractive force.

Based on our experimental observations we argue that the lift force is not the relevant driving force when $X$ tends to zero and we propose a simplified mechanical model that provides a satisfactory interpretation of the data with minimal assumptions. The proposed interpretation suggests that Shields's curve must tend toward a constant value when $X$ goes to zero. Moreover, it agrees with the suggestion by Yalin and Karahan (1978), thus providing a separate pattern on Shields's diagram for the critical condition $Y_{c r}$ in laminar flows. On the basis of straightforward considerations we highlight that the Shields diagram does not represent an intrinsic property of the bottom, i.e. its shear stress resistance. This is a geotechnical property that does not depend on the flow field and that would be represented by a constant value on the $X-Y$ plane. Instead, the pattern on the Shields diagram strongly reflects the structure of the flow field, in terms of homogeneity of spatial and temporal shear stress distribution.

The inception of sediment transport in turbulent flows is known to be stochastic since the driving force induced by turbulence is a random process. However, in viscous dominated flows the process remains stochastic because other random components of the process emerge. Accordingly, the critical condition is expressed by a probability distribution and has a conventional meaning. As a result, we propose to substitute Mantz's regression with relation 


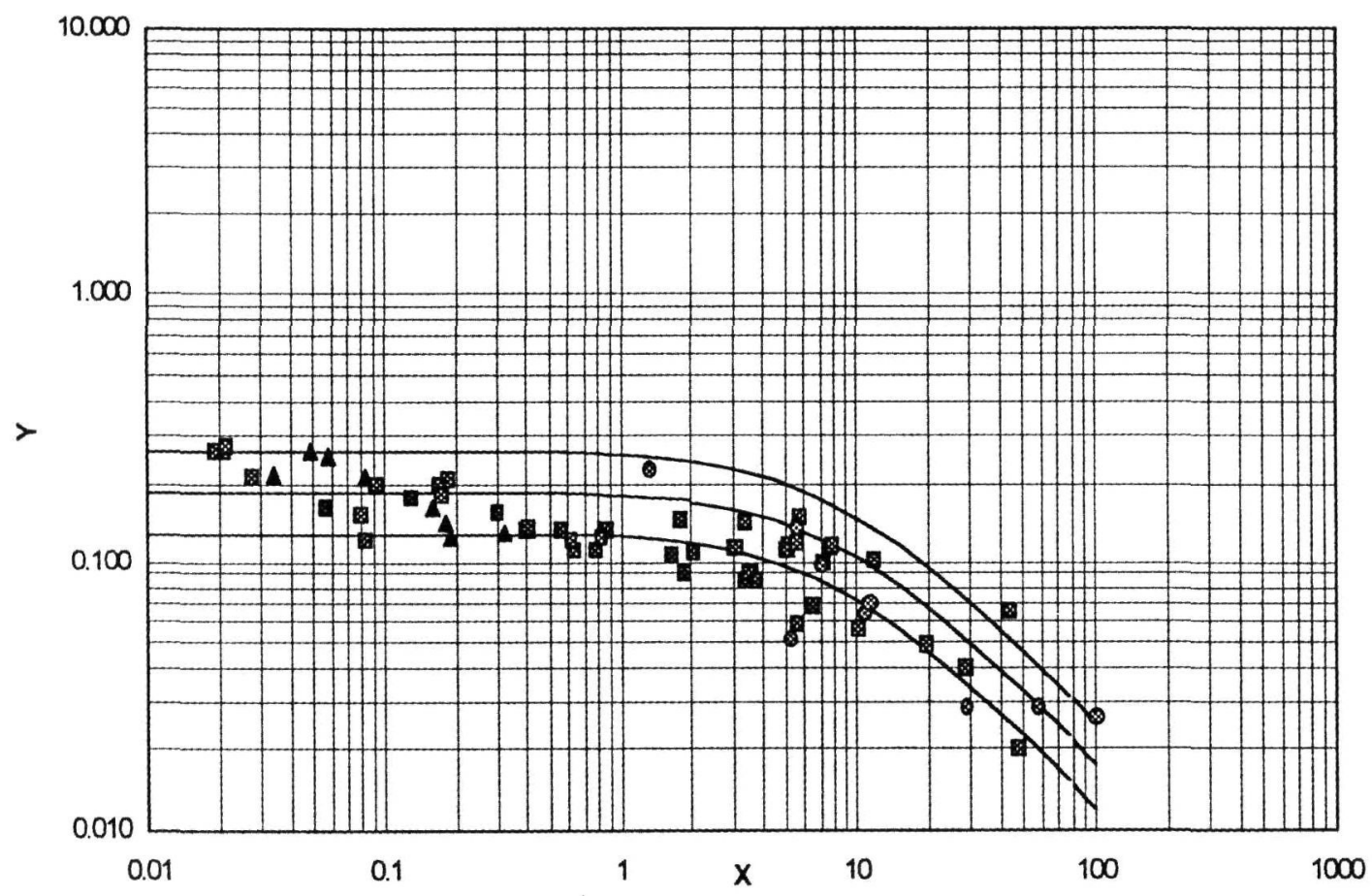

Figure 5: relation (25), in correpondence to the percentiles 10,20 and 30 and experimental data for viscous dominated flows (data from these experiments, Yalin and Karahan (1979) and Mantz (1977)).

(25), that explains the intrinsic uncertainty of the process for plane beds in terms of the probability distribution of the grain repose angle.

This work was partially supported by funds granted by Ministero della Università e della ricerca Scientifica e Tecnologica, Progetti $40 \%$, 'Processi Fluviali: Osservazione, Analisi e Controllo', lead by Giovanni Seminara and also by funds CNR 9800581PF42. The research contributed to the partial fulfillment of the doctoral thesis of the first author.

\section{References}

Chang, F.M., Simons, D.B., and Richardson E.V., Total bed material discharge in alluvial channels, Proc. $12^{\text {th }}$ Congress IAHR, Fort Collins, Co, 1967.

Coleman, N. L., A theoretical and experimental study of drag and lift forces acting on a sphere resting on a hypothetical stream bed, Proceedings, 12th Congress International Association for Hydraulic Research, Vol. 3, 1967.

Davies T. R., Samad M. F. Fluid dynamic lift on a bed particle, Journal of the Hydraulic division, ASCE, Vol. 104, 1978.

DuBoys, M.P. Etudes du Regime et l'Action Exercée par les Eaux sur un Lit à Fond de Graviers Indefiniment Affouilable, Annales de Ponts et Chaussés, Ser. 5, 18, 1879.

Emmetт, W. W., "Overland flow" in Hillslope hydrology, edited by M.J. Kirkby, Wiley, 145-176, 1978.

Grass, A.J., Initial instability of Fine Bed Sand, Journal of the Hydraulic division, ASCE, Vol 96, 1970.

IKEDA, S. Incipient motion of sand particles on side slopes, Journal of the Hydraulic division, ASCE, Vol 108, No. HY1, 1982.

Lavelle W., Mofjeld H. O., Do critical stresses for incipient motion and erosion really exist?, Journal of the Hydraulic divi- sion, ASCE, Vol 113, No.3, 1987a.

Lavelle W., MofJeld H. O., Bibliography on sediment threshold velocity, Journal of the Hydraulic division, ASCE, Vol 113, No.3, $1987 b$.

Kirchner, J.W., Dietrich, W.E., Iseya, F., Ikeda, H., The variability of critical shear stress, friction angle, and grain protrusion in water-worked sediments, Sedimentology, 37, 647672, 1990.

Mantz, P.A., Incipient Transport of Fine Grains and Flakes by Fluids - Extended Shields Diagram, Journal of the Hydraulics Division, ASCE, Vol. 103, 601-615, 1977.

McNown, J.S., Particles in slow motion, La Houille Blanche, Vol. 6, No. 5, 1951

Meyer-Peter, E., Müller, R. Formulas for bed load transport, Proc. Int. ass. Hydraulic Research, 3rd Ann. Conf., Stockholm, 39-64, 1948.

NaRAYANAN, R. Inception of Sediment Transport, Discussion, Journal of the Hydraulics Division, ASCE, Vol. 106, No. HY10, 1715-1716, 1980.

Pilotti, M., Menduni, G. and Castelli E., Monitoring the Inception of Sediment Transport by Image Processing Techniques, Experiments in Fluids, 23, 3, 202-208, 1997.

ReEs, A.I., Some flume experiments with a fine silt, Sedimentology, Vol. 6, 1966, pp.209-240.

Shields, A., Anwendung der Ahnlichkeistmechanik und der turbulenzforschung auf die geschiebebewegung, Mitteilungen der Preuss. Versuchsanst. f. Wasserbau u. Schiffbau, Berlin, Heft 26, 1936.

Swamee, P.K., C.S.P. OJHa, Drag coefficient and fall velocity of nonspherical particles, Journal of the Hydraulic Division, ASCE, Vol. 117, No. 5, 1991, pp.660-667.

Wang SAnY-Yi, Wen Shen Hsien, Incipient Sediment Motion 
and Riprap Design, Journal of the Hydraulic division, ASCE, Vol. 111, No. 3, March 1985.

Watters, G. Z., RaO M. V., Hydrodynamics effects of seepage on bed particles, Journal of the Hydraulic division, ASCE, Vol. 97, 1971.

White, C.M., The equilibrium of grains on the bed of a stream, Proceedings of the Royal Society, London, England, Vol. 174A, 1940.

White, S.J., Plane Bed Thresholds of fine Grained Sediments, Nature, vol. 228, Oct., pp. 152-153, 1970.

White, F.M., Viscous Fluid Flow, McGraw Hill, New York, 1974.

Yalin, M.S., An expression for bed load transportation, Proc. ASCE, Vol. 89, HY3, 1963.

Yalin, M.S., Mechanics of sediment transport, Pergamon Press, 1977.

YALIN, M.S., and KARAHAN, E., Inception of sediment Transport, Journal of the Hydraulics Division, ASCE, Vol. 105, HY11,1433-1443, 1979.

Zhang, W., Cundy, T. W., Laminar Einstein bed load equation for overland sheet flow, Journal of Hydraulic Engineering, ASCE, Vol. 113, No. 12, 1987.

\section{Notations}

$\Pi_{q} \quad$ dimensionless bed load discharge [-]

$X \quad$ grain Reynolds number [-]

$Y \quad$ mobility number [-]

$Y_{c r} \quad$ critical mobility number [-]

$Y_{n} \quad \mathrm{n} t h$ percentile critical mobility number [-]

$Z \quad$ relative roughness [-]

$W \quad$ liquid and solid phase density ratio [-]
Re stream Reynolds number [-]

$\mathrm{Fr} \quad$ Froude number [-]

$C_{D} \quad$ drag coefficient for a grain [-]

$q$ dimensional bed load discharge $\left[\mathrm{kg} / \mathrm{s}^{3}\right]$

$Q \quad$ volumetric liquid discharge $\left[\mathrm{m}^{3} / \mathrm{s}\right]$

$\rho \quad$ fluid density $\left[\mathrm{kg} / \mathrm{m}^{3}\right]$

$\beta \quad$ exponent for Shields curve [-]

$\alpha \quad$ ratio between $y_{\text {ref }}$ and D [-]

$\mu \quad$ dinamic viscosity coefficient $[\mathrm{Pa} \cdot \mathrm{s}]$

$v \quad$ kinematic viscosity coefficient $\left[\mathrm{m}^{2} / \mathrm{s}\right]$

$\gamma \quad$ fluid specific weight $\left[\mathrm{N} / \mathrm{m}^{3}\right]$

$\gamma_{s} \quad$ sediment submerged specific weight $\left[\mathrm{N} / \mathrm{m}^{3}\right]$

$\rho_{s} \quad$ grain density $\left[\mathrm{kg} / \mathrm{m}^{3}\right]$

$\Phi$ mass angle of repose of the granular mixture $\left[{ }^{\circ}\right]$

$\varphi \quad$ repose angle for a grain $\left[{ }^{\circ}\right]$

$D$ characteristic linear dimension of the sediment [m]

$R \quad$ hydraulic radius [m]

$h$ flow depth [m]

$y$ distance from the bed $[\mathrm{m}]$

$y_{\text {ref }}$ reference depth $[\mathrm{m}]$ for computation of $U_{\text {ref }}$

$U$ average flow velocity $[\mathrm{m} / \mathrm{s}]$

$U_{\text {ref }}$ reference flow velocity $[\mathrm{m} / \mathrm{s}]$ for computation of $F_{D}$

$u \quad$ local flow velocity $[\mathrm{m} / \mathrm{s}]$

$\nu_{*} \quad$ shear velocity $[\mathrm{m} / \mathrm{s}]$

$L \quad$ lift force [N]

$F_{D} \quad$ drag force [N]

$w \quad$ submerged grain weight $[\mathrm{N}]$

$J \quad$ energy slope [-]

$\tau_{o} \quad$ average bottom shear stress $[\mathrm{Pa}]$

$a, b$ adimensional parameters for computation of $C_{D}$

$n$ percentile of friction angle distribution [-] 